\title{
Feedback from Horizontal Cells to Rod Photoreceptors in Vertebrate Retina
}

\author{
Wallace B. Thoreson, ${ }^{1,2}$ Norbert Babai, ${ }^{1}$ and Theodore M. Bartoletti ${ }^{1,2}$ \\ Departments of ${ }^{1}$ Ophthalmology and Visual Science and ${ }^{2}$ Pharmacology and Experimental Neuroscience, University of Nebraska Medical Center, Omaha, \\ Nebraska 68198
}

Retinal horizontal cells (HCs) provide negative feedback to cones, but, largely because annular illumination fails to evoke a depolarizing response in rods, it is widely believed that there is no feedback from HCs to rods. However, feedback from HCs to cones involves small changes in the calcium current $\left(I_{\mathrm{Ca}}\right)$ that do not always generate detectable depolarizing responses. We therefore recorded $I_{\mathrm{Ca}}$ directly from rods to test whether they were modulated by feedback from HCs. To circumvent problems presented by overlapping receptive fields of HCs and rods, we manipulated the membrane potential of voltage-clamped HCs while simultaneously recording from rods in a salamander retinal slice preparation. Like HC feedback in cones, hyperpolarizing HCs from -14 to $-54,-84$, and $-104 \mathrm{mV}$ increased the amplitude of $I_{\mathrm{Ca}}$ recorded from synaptically connected rods and caused hyperpolarizing shifts in $I_{\mathrm{Ca}}$ voltage dependence. These effects were blocked by supplementing the bicarbonate-buffered saline solution with HEPES. In rods lacking light-responsive outer segments, hyperpolarizing neighboring $\mathrm{HCs}$ with light caused a negative activation shift and increased the amplitude of $I_{\mathrm{Ca}}$. These changes in $I_{\mathrm{Ca}}$ were blocked by HEPES and by inhibiting HC light responses with a glutamate antagonist, indicating that they were caused by HC feedback. These results show that rods, like cones, receive negative feedback from HCs that regulates the amplitude and voltage dependence of $I_{\mathrm{Ca}}$. HC-to-rod feedback counters light-evoked decreases in synaptic output and thus shapes the transmission of rod responses to downstream visual neurons.

Key words: synaptic transmission; $\mathrm{pH}$; scotopic vision; calcium current; feedback; horizontal cell

\section{Introduction}

A principal function of retinal horizontal cells (HCs) is to provide negative feedback to cone photoreceptors, thereby contributing to the formation of center-surround receptive fields (for review, see Burkhardt, 1993; Kamermans and Spekreijse, 1999). Although feedback from HCs to cones is well established, a number of investigators concluded that HCs do not provide feedback to rods, largely because wide-field or annular illumination failed to evoke depolarizing responses in rods (Brown and Pinto, 1974; Copenhagen and Owen, 1976; Miyachi et al., 1984; Lasansky, 1986). However, rods in lower vertebrates are coupled extensively with one another, creating large receptive fields that overlap extensively with HC receptive fields (Copenhagen and Owen, 1976; Attwell et al., 1984; Zhang and Wu, 2005) and can obscure feedback interactions. Furthermore, it is now clear that feedback from HCs to cones produces small changes in L-type calcium currents $\left(I_{\mathrm{Ca}}\right)$ of cones that do not necessarily result in large depolarizing responses (Gerschenfeld et al., 1980; Verweij et al., 1996). In support of the possibility of feedback from HCs to rods, Normann

\footnotetext{
Received Jan. 29, 2008; revised April 21, 2008; accepted April 24, 2008.

This work was supported by National Eye Institute Grant EY-10542 and Research to Prevent Blindness. We thank Dr. Dwight Burkhardt for helpful discussion.

Correspondence should be addressed to Wallace B. Thoreson, Ophthalmology Department, University of Nebraska Medical Center, Durham Research Center, Room 4050, Omaha, NE 68198-5840. E-mail: wbthores@unmc.edu.

DOI:10.1523/JNEUROSCI.0403-08.2008

Copyright $\odot 2008$ Society for Neuroscience $\quad$ 0270-6474/08/285691-05\$15.00/0
}

and Pochobradsky (1976) reported that wide-field illumination stimulated delayed oscillations in the rod membrane potential.

We reexamined the question of whether rods receive feedback from HCs by studying $I_{\mathrm{Ca}}$ in voltage-clamped rods. To circumvent the problem of overlapping receptive fields in rods and HCs, we directly manipulated the membrane potential of simultaneously recorded HCs. We also examined light-evoked feedback interactions by recording from rods that lacked outer segments. The results of these experiments show that, like feedback from HCs to cones (Verweij et al., 1996; Hirasawa and Kaneko, 2003; Cadetti and Thoreson, 2006), HC hyperpolarization increases the amplitude of rod $I_{\mathrm{Ca}}$ and shifts its activation to more negative potentials. Also like HC-to-cone feedback, HC-to-rod feedback was blocked by application of the $\mathrm{pH}$ buffer, HEPES, or inhibition of HC glutamate receptors. The net effect of HC-to-rod feedback during a light flash is to increase $\operatorname{rod} I_{\mathrm{Ca}}$ and thus increase rod synaptic output. By shaping transmission at the first synapse in the rod pathway, HC-to-rod feedback is likely to influence vision under scotopic and mesopic conditions.

\section{Materials and Methods}

Experiments were performed using retinal slices from aquatic tiger salamanders (Ambystoma tigrinum) because of their large rods. Methods were similar to those described previously (Rabl et al., 2005). Animals were handled according to protocols approved by the University of $\mathrm{Ne}$ braska Medical Center Animal Care and Use Committee. For experiments requiring light responses, we prepared slices under infrared illumination using night vision goggles (Nitemate NAV3; Litton Industries). 
Slices were superfused at $\sim 1 \mathrm{ml} / \mathrm{min}$ with a solution containing the following (in $\mathrm{mM}$ ): 101 $\mathrm{NaCl}, 22 \mathrm{NaHCO}_{3}, 2.5 \mathrm{KCl}, 2 \mathrm{CaCl}_{2}, 0.5 \mathrm{MgCl}_{2}$, and 9 glucose. This solution attained a $\mathrm{pH}$ of 7.35-7.37 after bubbling with $95 \% \mathrm{O}_{2} / 5 \% \mathrm{CO}_{2}$. The same $\mathrm{pH}$ was also attained after adding 1 mm kynurenic acid to the superfusate. In some experiments, $\mathrm{pH}$ buffering capacity was increased by adding $10 \mathrm{~mm}$ HEPES. While bubbling with $95 \% \mathrm{O}_{2} / 5 \% \mathrm{CO}_{2}$, the $\mathrm{pH}$ of the HEPES-containing solution was adjusted with $1 \mathrm{M} \mathrm{NaOH}$ to match that of the control bicarbonate-buffered solution.

Whole-cell recordings were obtained using 10-15 $\mathrm{M} \Omega$ patch electrodes fabricated from borosilicate glass ( $1.2 \mathrm{~mm}$ outer diameter, 0.95 $\mathrm{mm}$ inner diameter, with internal filament; World Precision Instruments) on a PP-830 micropipette puller (Narishige USA). The pipette solution for HCs contained the following (in $\mathrm{mm}$ ): 94 Cs-gluconate, 9.4 tetraethylammonium (TEA)-Cl, $1.9 \mathrm{MgCl}_{2}, 9.4 \mathrm{MgATP}, 0.5$ GTP, 5 EGTA, and 32.9 HEPES, pH 7.2. The pipette solution for rods contained the following (in mM): 15 Cs-gluconate, 70 Cs-glutamate, 10 TEA-Cl, $3.5 \mathrm{NaCl}, 10$ HEPES, 5 EGTA, 1 $\mathrm{CaCl}_{2}, 10 \mathrm{MgATP}, 0.5 \mathrm{GTP}$, and 2 glucose, $\mathrm{pH}$ 7.2. Membrane potential values were corrected for a junction potential of $-14 \mathrm{mV}$ calculated with pClamp's junction potential calculator. Rods and HCs were voltage clamped simultaneously using a Multiclamp patch-clamp amplifier (Molecular Devices). Currents were acquired using a Digidata 1322 interface and pClamp 9.2 software (Molecular Devices).

Rods were identified by shape and HCs by their characteristic responses and morphology (Thoreson et al., 1997). Using pClamp's mem-

brane test routine, $R_{\mathrm{a}}, R_{\mathrm{m}}$, and $C_{\mathrm{m}}$ of rod recordings were found to average $43.0 \pm 2.6 \mathrm{M} \Omega, 291 \pm 22 \mathrm{M} \Omega$, and $23.9 \pm 4.4 \mathrm{pF}(n=31)$, respectively. In HCs, $R_{\mathrm{a}}, R_{\mathrm{m}}$, and $C_{\mathrm{m}}$ averaged $47.9 \pm 4.9 \mathrm{M} \Omega, 269 \pm 57$ $\mathrm{M} \Omega$, and $55.1 \pm 6.1 \mathrm{pF}(n=17)$, respectively. EPSCs evoked in HCs by depolarization of simultaneously voltage-clamped presynaptic rods exhibited a reversal potential near $0 \mathrm{mV}$, as expected for glutamate-gated cation channels $(n=13)$.

Rod $I_{\mathrm{Ca}}$ was measured using a ramp voltage protocol $(-104$ to +46 $\mathrm{mV}, 0.5 \mathrm{mV} / \mathrm{ms}$ ) applied from a steady holding potential of $-84 \mathrm{mV}$. To fit $I_{\mathrm{Ca}}$ with a Boltzmann function, the fitting region extended from baseline to just beyond the peak of $I_{\mathrm{Ca}}$ to avoid contributions from residual outward $\mathrm{K}^{+}$currents at more positive potentials. The rod membrane resistance between -90 and $-70 \mathrm{mV}$ was subtracted digitally. $\mathrm{HC}$ holding potential was varied among $-104,-84,-54$, and $-14 \mathrm{mV}$. We averaged two trials in opposite sequence to minimize effects of run-up or run-down (e.g., one representative HC holding potential sequence: -54 , $-84,-104,-14,-14,-104,-84,-54 \mathrm{mV})$. Sequences were varied between cells to avoid order effects.

The criterion for statistical significance was chosen to be $p<0.05$ and evaluated using Student's $t$ test and GraphPad Prism 4.0. Variability is reported as \pm SEM.

\section{Results}

To test for feedback from HCs to rods, we obtained simultaneous whole-cell recordings from a rod and postsynaptic $\mathrm{HC}$ in the salamander retinal slice (Fig. 1). The L-type $I_{\mathrm{Ca}}$ in rods was recorded using a ramp voltage protocol. When HCs were held at $-54 \mathrm{mV}$, the best fit to rod $I_{\mathrm{Ca}}$ by a Boltzmann function adjusted for driving force yielded the following parameters: peak amplitude $=129.9 \pm 12.1 \mathrm{pA} ; V_{50}=-35.8 \pm 1.0 \mathrm{mV}$; slope $=-7.8 \pm 0.4 ; E_{\mathrm{rev}}= \pm 8.9 \pm 5.7 \mathrm{mV}(n=22)$. Shifting the $\mathrm{HC}$ holding potential from -54 to $-84 \mathrm{mV}$ caused a small increase in the simultaneously recorded $\operatorname{rod} I_{\mathrm{Ca}}$ and shifted its activation toward more negative potentials (Fig. $1 B$ ). Hyperpolarizing the $\mathrm{HC}$ further to $-104 \mathrm{mV}$ caused a further increase in $I_{\mathrm{Ca}}$ and shifted $I_{\mathrm{Ca}}$ activation to still more negative potentials. On the other hand, depolarizing the $\mathrm{HC}$ to $-14 \mathrm{mV}$ caused $I_{\mathrm{Ca}}$ to decrease and activate at more positive potentials. To quantify the shift in voltage dependence, we measured the voltage at which the current was half maximal $\left(V_{50}\right)$. Figure $1 C$ shows the average shift in $V_{50}$ produced by changes in HC potential relative to the value of $V_{50}$ determined when the $\mathrm{HC}$ was held at $-54 \mathrm{mV}$. The shift in $V_{50}$ was linear with changes in $\mathrm{HC}$ membrane potential, with a shift of $-0.33 \mathrm{mV}$ per 10 $\mathrm{mV}$ hyperpolarization of the $\mathrm{HC}$. The change in $I_{\mathrm{Ca}}$ amplitude was also linearly related to $\mathrm{HC}$ membrane potential, with a reduction of $2.4 \%$ per $10 \mathrm{mV}$ hyperpolarization of the $\mathrm{HC}$ (Fig. 1D). These results indicate that HCs provide feedback to rods similar to the feedback they provide to cones, in which HC hyperpolarization causes a negative activation shift and increases the peak amplitude of $I_{\mathrm{Ca}}$ recorded presynaptically (Verweij et al., 1996; Hirasawa and Kaneko, 2003; Cadetti and Thoreson, 2006).

We determined whether cell pairs were synaptically connected by applying a depolarizing test step from -84 to $-24 \mathrm{mV}(100$ $\mathrm{ms})$ to the rod. In all 17 cell pairs that exhibited feedback interactions, the test step evoked a postsynaptic current in the HC. In contrast, in all three rod/HC pairs in which postsynaptic currents were not observed, $\mathrm{HC}$ polarization did not detectably influence 

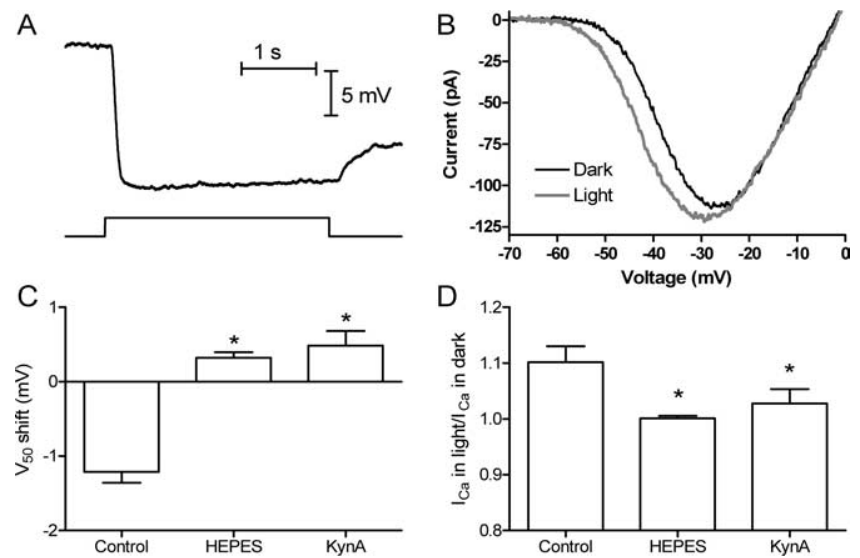

Figure 2. Hyperpolarizing HCs by light caused a negative shift in voltage dependence and increased the amplitude of rod $I_{\mathrm{ca}} . \boldsymbol{A}$, Light response of a horizontal cell evoked by a $3 \mathrm{~s}$ white light flash. $B, I_{C a}$ recorded using a ramp voltage protocol from a rod lacking its outer segment in darkness (black trace) and white light (gray trace). $C$, The leftward shift in the $V_{50}$ of $I_{C_{a}}$ induced by light in control conditions was blocked by application of HEPES $(10 \mathrm{~mm} ; n=11 ; p<0.0001)$ or kynurenic acid (KynA; $1 \mathrm{~mm} ; n=9 ; p<0.0001)$. $\boldsymbol{D}$, The light-induced increase in $I_{\text {са }}$ peak amplitude was also blocked by application of HEPES $(10 \mathrm{~mm} ; n=11$; paired $t$ test, $p=0.04)$ or kynurenic acid $(1 \mathrm{~mm} ; n=9$; paired $t$ test, $p=0.026) .{ }^{*} p<0.05$.

the amplitude or voltage dependence of $\operatorname{rod} I_{\mathrm{Ca}}$. Polarization of synaptically connected ON $(n=3)$ or OFF $(n=5)$ bipolar cells also had no effect on $\operatorname{rod} I_{\mathrm{Ca}}$, indicating that feedback effects are limited to HCs.

HC-to-cone feedback is blocked by the addition of HEPES to the extracellular solution (Hirasawa and Kaneko, 2003; Vessey et al., 2005; Cadetti and Thoreson, 2006; Davenport et al., 2008). Likewise, addition of HEPES (10 mM) to the $\mathrm{HCO}_{3}$ containing superfusate for $\geq 4 \mathrm{~min}$. blocked the changes in amplitude and voltage dependence of $I_{\mathrm{Ca}}$ in rods produced by HC polarization (Fig. 1C). These changes recovered after washout of HEPES (data not shown). HEPES did not significantly alter the input resistance of rods ( $p=0.98$, paired $t$ test; $n=15)$ or HCs $(p=0.70$, paired $t$ test; $n=18)$. Feedback effects on rod $I_{\mathrm{Ca}}$ were also not altered by the combined application of picrotoxin $(100 \mu \mathrm{M})$ and strychnine $(1 \mu \mathrm{M} ; n=3)$. The ability of HEPES but not picrotoxin and strychnine to block effects of $\mathrm{HC}$ polarization on rod $I_{\mathrm{Ca}}$ suggests that feedback from HCs to rods involves a mechanism similar to feedback from HCs to cones.

We tested whether hyperpolarizing HCs by light produced effects on $\operatorname{rod} I_{\mathrm{Ca}}$ similar to directly hyperpolarizing HCs during paired recordings. To minimize direct effects of light on the rod, we recorded from rods lacking outer segments. Rods lacking outer segments nonetheless exhibited small responses to light because of responses of neighboring rods that are connected by gap junctions (Copenhagen and Owen, 1976; Attwell et al., 1984; Zhang and $\mathrm{Wu}, 2005)$. A voltage ramp was applied to a rod after $\sim 1$ s of illumination with a saturating white light to hyperpolarize surrounding HCs (Fig. 2A). HC membrane potentials averaged $-59.0 \pm 5.7 \mathrm{mV}(n=8)$ in darkness and $-75.5 \pm 5.3 \mathrm{mV}$ after $1 \mathrm{~s}$ of illumination. There was no significant change in $\mathrm{HC}$ membrane potential over a $500 \mathrm{~ms}$ period of the light response from 0.5 to $1 \mathrm{~s}(+0.26 \pm$ $0.11 \mathrm{mV} ; n=8)$, indicating that the HC membrane potential remained essentially constant during the $300 \mathrm{~ms}$ needed to complete the voltage ramp in a rod. In rods with light-evoked currents $<10 \mathrm{pA}$, suggesting a minimal degree of rod-rod coupling, light caused a significant leftward shift in the $V_{50}$ of
$I_{\mathrm{Ca}}$ averaging $-1.23 \pm 0.17 \mathrm{mV}(n=19 ; p<0.0001)$ and increase in $I_{\mathrm{Ca}}$ amplitude of $10.8 \pm 3.6 \%(p=0.0076)$ (Fig. 2). The changes in $I_{\mathrm{Ca}}$ produced by light-evoked hyperpolarization of HCs were similar to those produced by directly hyperpolarizing $\mathrm{HCs}$ from -54 to $-84 \mathrm{mV}$ during paired recording (Fig. 1).

Like feedback effects from HCs to rods in paired recordings, the leftward shift and increased amplitude of $I_{\mathrm{Ca}}$ evoked by light were reversibly blocked by HEPES (10 mM) (Fig. 2). By causing a hyperpolarizing block of HC light responses, glutamate antagonists block light-mediated feedback from HCs (Thoreson and Burkhardt, 1990; Hirasawa and Kaneko, 2003; Verweij et al., 2003). The glutamate antagonist kynurenic acid (1 mM) blocked light-induced changes in the amplitude and voltage dependence of $I_{\mathrm{Ca}}$ recorded from rods lacking outer segments (Fig. 2). The hyperpolarization of HCs by bath application of kynurenic acid also caused a significant leftward shift in the $V_{50}$ of $I_{\mathrm{Ca}}$ averaging $-5.1 \pm 1.4 \mathrm{mV}(n=8 ; p=0.008)$. Kynurenic acid may cause a larger shift than light because blocking all of the glutamate receptors causes greater HC hyperpolarization than does a lightevoked decrease in release of glutamate from photoreceptors (Thoreson and Burkhardt, 1990). After blocking feedback with kynurenic acid or HEPES, light sometimes caused a small rightward shift in $I_{\mathrm{Ca}}$. This may be attributable to hyperpolarization of the rod terminal produced by the hyperpolarizing light responses of coupled rods. The blocking effects of HEPES and kynurenic acid suggest that the leftward shift and increased amplitude of rod $I_{\mathrm{Ca}}$ produced by light are caused by HC feedback.

\section{Discussion}

The present results show that hyperpolarization of $\mathrm{HCs}$ (whether by light or direct hyperpolarization of voltageclamped HCs) exerts a feedback effect on rod terminals that increases the amplitude of $I_{\mathrm{Ca}}$ and shifts its voltage dependence in a hyperpolarizing direction. The net result is to enhance tonic activation of $I_{\mathrm{Ca}}$ in rods at physiological membrane potentials. Feedback interactions required synaptic contact between rods and HCs, but polarization of bipolar cells did not influence rod $I_{\mathrm{Ca}}$, suggesting that feedback onto rod terminals is limited to HCs. An enhancement of $I_{\mathrm{Ca}}$ by HC feedback would account for oscillatory potentials generated by illumination of the receptive field surround in rods (Normann and Pochobradsky, 1976).

Bright light causes rods to hyperpolarize from a membrane potential of approximately $-40 \mathrm{mV}$ in darkness to a sustained membrane potential of between -45 and $-50 \mathrm{mV}$ in light (Attwell et al., 1987; Thoreson et al., 2003). When measured with a ramp applied from the holding potential of $-84 \mathrm{mV}$, we found that $I_{\mathrm{Ca}}$ averaged approximately $-70 \mathrm{pA}$ in amplitude at $-40 \mathrm{mV}$. However, when a rod is maintained at $-40 \mathrm{mV}$ for many seconds, $I_{\mathrm{Ca}}$ diminishes by $\sim 50 \%$ because of $I_{\mathrm{Ca}}$ inactivation and the depletion of extracellular calcium ions from the synaptic cleft (Rabl and Thoreson, 2002; Thoreson et al., 2003). Nonetheless, the shape of the current/voltage relationship can be used to predict light-evoked changes in $I_{\mathrm{Ca}}$ (Thoreson et al., 2003) and suggests that hyperpolarizing a rod to a potential of -45 to $-50 \mathrm{mV}$ reduces $I_{\mathrm{Ca}}$ by $16-54 \%$ from its tonic level in darkness. In recordings from rods that lacked light-sensitive outer segments, light caused a $-1.2 \mathrm{mV}$ activation shift and $10 \%$ increase in the peak amplitude of rod $I_{\mathrm{Ca}}$. These light-evoked changes in $\operatorname{rod} I_{\mathrm{Ca}}$ appeared to be caused by feedback from HCs, because they were blocked by HEPES and a glutamate antagonist, kynurenic acid (Thoreson and 
Burkhardt, 1990; Hirasawa and Kaneko, 2003; Vessey et al., 2005; Cadetti and Thoreson, 2006; Davenport et al., 2008). The feedback-induced leftward shift and increase in peak amplitude would be predicted to increase $I_{\mathrm{Ca}}$ at the rod membrane potential in light $(-45$ to $-50 \mathrm{mV})$ by $10-14 \%$ of its amplitude in darkness, thereby restoring a large fraction of the reduction in $I_{\mathrm{Ca}}$ that occurs when a rod goes from dark to light. $\mathrm{HC}$ feedback may exert an even larger influence on $\operatorname{rod} I_{\mathrm{Ca}}$ in intact retina than in rods recorded at the surfaces of retinal slices, where at least one-half of the neighboring horizontal cells were excised during the slicing procedure.

The mechanisms underlying HC-to-cone feedback remain under investigation, with proposals that feedback may be attributable to GABA, pH, or an ephaptic mechanism involving hemigap junctions (Thoreson and Burkhardt, 1990; Kamermans et al., 2001; Hirasawa and Kaneko, 2003; Tatsukawa et al., 2005). The goal of pharmacological experiments in the present study was not to distinguish among these different possibilities but to test whether agents that are known to block HC-to-cone feedback can also block feedback onto rod terminals. The ability of HEPES and kynurenic acid, but not picrotoxin and strychnine, to block feedback-mediated changes in $I_{\mathrm{Ca}}$ indicates that HC-to-rod feedback involves mechanisms similar to feedback at cone synapses (Thoreson and Burkhardt, 1990; Hirasawa and Kaneko, 2003; Vessey et al., 2005; Cadetti and Thoreson, 2006; Davenport et al., 2008).

Proposed functions of HC feedback in cones (Burkhardt, 1993; Kamermans and Spekreijse, 1999) suggest possible analogous functions of HC-to-rod feedback. (1) A major function of HC-to-cone feedback is the creation of center-surround receptive fields that enhance edge detection (Baylor et al., 1971). Consistent with such a function for horizontal cell-torod feedback, bipolar cells receptive fields in salamander retina exhibit center-surround antagonism under conditions in which synaptic input is provided entirely by rods (Hare and Owen, 1990). However, there is no evidence for centersurround receptive fields in mouse rod bipolar cells (Bloomfield and Xin, 2000). Although it has not yet been shown directly, the presence of HC feedback in mammalian rods is suggested by the anatomical finding that axon terminals of B-type HCs make synaptic contacts exclusively with rods (Hirano et al., 2005; Pan and Massey, 2007). (2) A second possible function of HC-to-rod feedback is suggested by the finding that $\mathrm{HC}$ feedback contributes to light adaptation in cones (Burkhardt, 1995). Similar to cones, feedback-mediated increases in $I_{\mathrm{Ca}}$ and synaptic release from rods would be predicted to restore postsynaptic sensitivity to subsequent light flashes and thus contribute to light adaptation. (3) HC-tocone feedback has been proposed to enhance temporal frequency response characteristics (Burkhardt, 1993). By making postsynaptic responses more transient, feedback-mediated increases in synaptic transmission from rods might also improve the ability of bipolar cells to follow flickering stimuli under dim light conditions. (4) HC feedback to cones contributes to color opponent interactions (Dacey, 2000; Twig et al., 2003). Many HCs in lower vertebrates receive inputs from both rods and cones, raising the possibility that $\mathrm{HC}$ feedback to rods may allow color opponent interactions in the rod pathway under mesopic conditions. However, such interactions seem unlikely in mammalian retina because of the strong segregation of rod and cone inputs into HCs (Pan and Massey, 2007).

In summary, by studying simultaneously recorded pairs of horizontal cells and rod photoreceptors, we discovered that feed- back from HCs can regulate the amplitude and voltage dependence of rod $I_{\mathrm{Ca}}$ using mechanisms similar to HC feedback in cones. During a light flash, HC-to-rod feedback partially restores the amplitude of $I_{\mathrm{Ca}}$ in rods and thus restores synaptic output. The consequences of horizontal cell feedback in rods for scotopic and mesopic vision have not yet been examined, but they may be similar to horizontal cell feedback in cones, where it has been proposed that feedback contributes to light adaptation, temporal frequency response characteristics of synaptic transmission, color opponency, and the generation of center-surround receptive fields.

\section{References}

Attwell D, Wilson M, Wu SM (1984) A quantitative analysis of interactions between photoreceptors in the salamander (Ambystoma) retina. J Physiol (Lond) 352:703-737.

Attwell D, Borges S, Wu SM, Wilson M (1987) Signal clipping by the rod output synapse. Nature 328:522-524.

Baylor DA, Fuortes MG, O'Bryan PM (1971) Receptive fields of cones in the retina of the turtle. J Physiol (Lond) 214:265-294.

Bloomfield SA, Xin D (2000) Surround inhibition of mammalian AII amacrine cells is generated in the proximal retina. J Physiol (Lond) 523:771-783.

Brown JE, Pinto LH (1974) Ionic mechanism for the photoreceptor potential of the retina of Bufo marinus. J Physiol (Lond) 236:575-591.

Burkhardt DA (1993) Synaptic feedback, depolarization, and color opponency in cone photoreceptors. Vis Neurosci 10:981-989.

Burkhardt DA (1995) The influence of center-surround antagonism on light adaptation in cones in the retina of the turtle. Vis Neurosci 12:877-885.

Cadetti L, Thoreson WB (2006) Feedback effects of horizontal cell membrane potential on cone calcium currents studied with simultaneous recordings. J Neurophysiol 95:1992-1995.

Copenhagen DR, Owen WG (1976) Functional characteristics of lateral interactions between rods in the retina of the snapping turtle. J Physiol (Lond) 259:251-282.

Dacey DM (2000) Parallel pathways for spectral coding in primate retina. Annu Rev Neurosci 23:743-775.

Davenport CM, Detwiler PB, Dacey DM (2008) Effects of $\mathrm{pH}$ buffering on horizontal and ganglion cell light responses in primate retina: evidence for the proton hypothesis of surround formation. J Neurosci 28:456-464.

Gerschenfeld HM, Piccolino M, Neyton J (1980) Feed-back modulation of cone synapses by L-horizontal cells of turtle retina. J Exp Biol 89:177-192.

Hare WA, Owen WG (1990) Spatial organization of the bipolar cell's receptive field in the retina of the tiger salamander. J Physiol (Lond) 421:223-245.

Hirano AA, Brandstatter JH, Brecha NC (2005) Cellular distribution and subcellular localization of molecular components of vesicular transmitter release in horizontal cells of rabbit retina. J Comp Neurol 488:70-81.

Hirasawa H, Kaneko A (2003) pH changes in the invaginating synaptic cleft mediate feedback from horizontal cells to cone photoreceptors by modulating $\mathrm{Ca}^{2+}$ channels. J Gen Physiol 122:657-671.

Kamermans M, Spekreijse H (1999) The feedback pathway from horizontal cells to cones. A mini review with a look ahead. Vision Res 39:2449-2468.

Kamermans M, Fahrenfort I, Schultz K, Janssen-Bienhold U, Sjoerdsma T, Weiler R (2001) Hemichannel-mediated inhibition in the outer retina. Science 292:1178-1180.

Lasansky A (1986) Depolarizing responses of turtle rods. Neurosci Res Suppl 4:S59-S67.

Miyachi E, Takahashi K, Murakami M (1984) Electrically evoked calcium responses in rods of the frog retina. Jpn J Physiol 34:307-318.

Normann RA, Pochobradsky J (1976) Oscillations in rod and horizontal cell membrane potential: evidence for feed-back to rods in the vertebrate retina. J Physiol (Lond) 261:15-29.

Pan F, Massey SC (2007) Rod and cone input to horizontal cells in the rabbit retina. J Comp Neurol 500:815-831.

Rabl K, Thoreson WB (2002) Calcium-dependent inactivation and depletion of synaptic cleft calcium ions combine to regulate rod calcium currents under physiological conditions. Eur J Neurosci 16:2070-2077.

Rabl K, Cadetti L, Thoreson WB (2005) Kinetics of exocytosis is faster in cones than rods. J Neurosci 25:4633-4640.

Tatsukawa T, Hirasawa H, Kaneko A, Kaneda M (2005) GABA-mediated 
component in the feedback response of turtle retinal cones. Vis Neurosci 22:317-324.

Thoreson WB, Burkhardt DA (1990) Effects of synaptic blocking agents on the depolarizing responses of turtle cones evoked by surround illumination. Vis Neurosci 5:571-583.

Thoreson WB, Nitzan R, Miller RF (1997) Reducing extracellular chloride suppresses dihydropyridine-sensitive calcium currents and synaptic transmission in amphibian photoreceptors. J Neurophysiol 77:2175-2190.

Thoreson WB, Tranchina D, Witkovsky P (2003) Kinetics of synaptic transfer from rods and cones to horizontal cells in the salamander retina. Neuroscience 122:785-798.

Twig G, Levy H, Perlman I (2003) Color opponency in horizontal cells of the vertebrate retina. Prog Retin Eye Res 22:31-68.

Verweij J, Kamermans M, Spekreijse H (1996) Horizontal cells feed back to cones by shifting the cone calcium-current activation range. Vision Res 36:3943-5393.

Verweij J, Hornstein EP, Schnapf JL (2003) Surround antagonism in macaque cone photoreceptors. J Neurosci 23:10249-10457.

Vessey JP, Stratis AK, Daniels BA, Da Silva N, Jonz MG, Lalonde MR, Baldridge WH, Barnes S (2005) Proton-mediated feedback inhibition of presynaptic calcium channels at the cone photoreceptor synapse. J Neurosci 25:4108-4117.

Zhang J, Wu SM (2005) Physiological properties of rod photoreceptor electrical coupling in the tiger salamander retina. J Physiol (Lond) 564: 849-862. 